\title{
Drilling of recycled carbon fibre-reinforced polymer (rCFRP) composites: analysis of burrs and microstructure
}

\author{
Norbert Geier $^{1}\left[\right.$ D . Dániel István Poór ${ }^{1} \cdot$ Csongor Pereszlai $^{1} \cdot$ Péter Tamás-Bényei $^{2,3}$
}

Received: 26 August 2021 / Accepted: 27 January 2022 / Published online: 13 February 2022

(c) The Author(s) 2022

\begin{abstract}
Since governments encourage sustainability, industries are making great efforts to reuse or recycle carbon fibre-reinforced polymer (CFRP) composites. Despite the promising early results concerning the material properties of recycled CFRP, there is no published knowledge available about their machinability. In this study, drilling-induced micro and macro-sized geometrical defects were analysed and compared in virgin and recycled CFRP. A total of 180 drilling experiments were carried out using uncoated solid carbide cutting tools. Six different CFRP composites were tested at different feeds. The burr characteristics and microstructure were analysed by optical and scanning electron microscopy. The analysis of variance (ANOVA) results suggest that the formation of drilling-induced burrs in CFRP reinforced by recycled chopped and nonwoven mats is less pronounced than in virgin CFRP. Micro- and macro-sized geometrical defects in both recycled and virgin milled CFRP were negligible. This study found no relevant objection to using recycled CFRP from the point of view of drilling-induced burrs and microstructure damage.
\end{abstract}

Keywords Recycled carbon fibres $\cdot$ rCFRP $\cdot$ Drilling $\cdot$ Burrs $\cdot$ Microstructure

\section{Introduction}

As carbon fibre-reinforced polymer (CFRP) composites have superior properties (such as excellent specific strength and dimensional stability [1,2]), they are widely used in high-tech industries, including the aerospace, defence and automotive industries [3]. Laws require these industrial sectors to reuse or recycle most of their products to decrease the ecological footprint and increase the sustainability of the processes. For some years now, it has been possible to recycle carbon fibres from CFRP composites not only in laboratories but also on an industrial scale [4]. Recycled

Norbert Geier

geier.norbert@gpk.bme.hu

1 Department of Manufacturing Science and Engineering, Faculty of Mechanical Engineering, Budapest University of Technology and Economics, Múegyetem rkp. 3, Budapest 1111, Hungary

2 Department of Polymer Engineering, Faculty of Mechanical Engineering, Budapest University of Technology and Economics, Múegyetem rkp. 3, Budapest 1111, Hungary

3 MTA-BME Research Group for Composite Science and Technology, Múegyetem rkp. 3, Budapest 1111, Hungary
CFRP can have almost as good material properties as virgin CFRP, although the applied recycling and sizing technologies have an impact on their properties and performance [5].

Okayasu and Kondo [6] analysed the tensile properties of recycled carbon fibre-reinforced polymer (rCFRP) composites. They found that the tensile strength of rCFRP depends significantly on the proportion and the size of the carbon reinforcements. A higher proportion of chopped carbon reinforcements increased tensile strength, but a higher proportion of milled reinforcements decreased it; however, the effect of the resin was negligible. Park et al. [7] observed that the thermal properties of rCFRP were significantly affected by the presence of residual epoxy resin. They highlighted that the thermal stability of rCFRP affects inherent composite properties. According to Rademacker et al. [8], the mechanical properties of rCFRP are comparable and, in some cases, even better than those of virgin CFRP. They highlighted that-despite the encouragement of sustainability by governments and society-there is often a lack of willingness to optimise the manufacturing processes of rCFRP. Hadigheh et al. [9] optimized the process parameters of the pyrolysis to reduce the cost and increase the energy efficiency of the recycling of CFRP. They analysed the impact of recycling processes on the surface characteristics 
of carbon fibres. They found that pyrolysis up to $425{ }^{\circ} \mathrm{C}$ followed by oxidation up to $550{ }^{\circ} \mathrm{C}$ with a heating rate of $10^{\circ} \mathrm{C} / \mathrm{min}$ and a specific isothermal dwelling time is optimal for good-quality production of recycled carbon fibres. Zhao et al. [10] developed a novel approach to recycling CFRP. They observed that rCFRP retained over $93 \%$ of the tensile strength and elastic modulus of virgin CFRP. Furthermore, they found the wettability properties of rCFRP better than those of virgin CFRP. Genna et al. [11] compared mechanical properties of rCFRP through quasi-static and dynamic tests. They found that the analysed rCFRP showed a strongly anisotropic character, and the excellent material properties of rCFRP make them suitable for a wide range of applications in the future.

Despite the promising early results concerning the material properties of rCFRP, there is no published knowledge available about their machining behaviour; the machinability analysis of rCFRP composites is therefore required. Based on the analogy of gained experiences in virgin CFRP machining, the following main phenomena and challenges are expected in the machining of rCFRP composites: (i) the recycled carbon fibres will have a significant wear effect on the cutting tool [12-14]; (ii) in the case of longer (compared to the minimum reinforcement length) fibres, the material properties are orientation-dependent; hence, the machinability of rCFRP will also be orientation-dependent [15-19]; (iii) improper machining technology will induce significant burr formation, delamination, fibre pull-outs and fragmentation [20-26].

Considering the expected challenges in the machining of rCFRP, the authors selected drilling for the first machining experiments on rCFRP. First, the effect of each dominant chip removal mechanism can be analysed, due to the $0-360^{\circ}$ rotation of the cutting tool. Second, based on the applications and machining needs of virgin CFRP [1], drilling will probably be the most often used form of machining in rCFRP. Burr occurrence at drilled holes in CFRP was experimentally investigated by $\mathrm{Xu}$ et al. [14]. They characterised drilling-induced burr by the burr area parameter. They showed that the larger the feed, the larger the burr area, because the larger feeds increase the thrust force and the cutting temperature; thus, the softened fibres get buckled easier and form more burrs. Nevertheless, the influence of feed on burr is unclear, as burr formation is not related directly to the chip cross-section; it is more influenced by proper clamping of the composite, solid embedding of the fibres and tool geometry [27].

Hrechuk et al. [28] analysed hole quality in CFRP. They characterised drilling-induced burrs based on the analysis of the contour of the holes. Their proposed methodology to quantify burrs in CFRP is based on two-dimensional digital image analysis of optically captured images of holes. Wang et al. [29] analysed drilling-induced surface damage in unidirectional CFRP. They highlighted that cutting edge radius and fibre cutting angle play an important role in burr forming mechanisms. The larger the cutting edge radius, the higher the risk of delamination and burr formation due to the higher risk of a bending-dominated chip removal mechanism. Xu et al. [19] proposed to quantify and measure drilling-induced burrs based on the analogy of quantifying conventional delamination. As delamination is often analysed through the analysis of the conventional delamination factor $\left(F_{d}=D_{\max } / D_{\text {nom }}\right.$, where $D_{\max }$ is the maximal diameter of the delaminated zone and $D_{\text {nom }}$ is the nominal hole diameter), the burrs can be analysed by the burr factor, that is the ratio of the burr area to the nominal area of the hole. Although machining-induced extra materials at the machined edges of the geometrical features in CFRP are often called uncut fibres [28] or delamination type II [30], the term burr is used in this study mainly because of its forming mechanisms and material content (not only reinforcing fibres, but matrix also).

The machinability of materials may be defined as a material property, as a factor in tool life, in terms of the cutting speed or other criteria [31]. Generally, the machinability of fibrous composites requires information on the (i) formation of chip, burr and delamination [32]; (ii) surface integrity [33]; (iii) tool life and tool wear rates [34]; (iv) specific cutting force, torque and shear stress [35]; (v) achievable micro and macro geometrical tolerances [36]; (vi) mechanical properties (e.g. hardness, resultant strength) [37]; and (vii) cutting temperature [38], at certain machining setups (machine tool, cutting tool, lubrication, temperature, etc.). This paper deals with the experimental analysis of drillinginduced burrs through digital image processing, and surface integrity through scanning electron microscopy.

In this experimental study, drilling-induced burr and micro geometrical damages are investigated in different reinforcement structures of rCFRP and CFRP composites. The main aim of the study is to compare drilling-induced burrs and microstructures in recycled and virgin CFRP. Numerous drilling experiments were performed in rCRRP and CFRP, and the geometrical responses were analysed by digital and scanning electron microscopy and digital image processing.

\section{Experimental setups}

\subsection{CFRP composites}

The machining experiments were performed on six different CFRP composites, as listed in Table 1. The CFRP composite plates were manufactured by compression moulding and silicone form casting with the use of virgin $(\mathrm{V})$ and recycled (R) carbon fibre reinforcements and epoxy resin (MR3010 resin and MH3124 hardener, in the mixing ratio of 100:33, 
Table 1 The investigated CFRP composite materials

\begin{tabular}{lllll}
\hline Code & Virgin/recycled & Reinforcement structure & $\begin{array}{l}\text { Average reinforcement } \\
\text { length }(\mu \mathrm{m})\end{array}$ & Manufacturing \\
\hline VA & Virgin & Chopped & $5873 \pm 606$ & Compression moulding \\
VB & Virgin & Nonwoven mat & quasi-infinite & Compression moulding \\
VC & Virgin & Milled & $45 \pm 28$ & Silicone form casting \\
RA & Recycled & Chopped & $6114 \pm 1439$ & Compression moulding \\
RB & Recycled & Nonwoven mat & quasi-infinite & Compression moulding \\
RC & Recycled & Milled & $77 \pm 51$ & Silicone form casting \\
\hline
\end{tabular}

respectively). The recycled carbon fibres were recycled by an international carbon fibre producer company using pyrolysis. Three different fibre reinforcement structures were analysed in this study: chopped (A), nonwoven mat (B) and milled $(C)$. The structures of the carbon reinforcements can be seen in Fig. 1. The average length of 300 elemental fibres was measured with an Olympus BX-51 optical microscope in each type of carbon fibre structure.

The carbon fibre-reinforced polymer composite sheets were produced by three different methods. Milled fibrereinforced composites were produced by silicone form casting; composites with chopped fibres and nonwoven mats were made by compression moulding. The nominal dimensions of the composite sheets produced were $200 \times 200 \times 4 \mathrm{~mm}$ (width $\times$ length $\times$ thickness). In silicone form casting, milled fibres were mixed with the epoxy component (MR3010) for 15 min with an IKA RW16 mechanical stirrer. After that, the hardener component (MH3124) was added and stirred homogeneously with the mixture for $4.5 \mathrm{~min}$ (3 times $1.5 \mathrm{~min}$; stirring, resting and stirring again) at room temperature. The complete mixture (with a nominal fibre content of $20 \mathrm{wt} \%$ ) was poured into a silicone mould and cured for $14 \mathrm{~h}$ at room temperature. Each solid composite sheet was post-cured for $2 \mathrm{~h}$ at $60{ }^{\circ} \mathrm{C}$ in a Despatch LBB2-27-1CE drying oven.

For the chopped fibre-reinforced composites, chopped fibres were mixed with the epoxy component (MR3010) for 15 min with an IKA RW16 mechanical stirrer. After that, the hardener component (MH3124) was added and stirred homogeneously with the mixture for $4.5 \mathrm{~min}$ (3 times 1.5 min: stirring, resting and stirring again) at room temperature. The complete mixture (with a nominal fibre content of $20 \mathrm{wt} \%$ ) was poured into a properly sealed, preheated $\left(60^{\circ} \mathrm{C}\right)$ alumina mould. It was pressed in a Metal Fluid Engineering $30 \mathrm{~T}$ hydraulic hot-press $\left(80^{\circ} \mathrm{C}, 100 \mathrm{bar}\right)$ for $20 \mathrm{~min}$ after mould closing. After pressing, the mould was cooled down to room temperature between closed press platens.

Nonwoven mat-reinforced composites were produced by a combination of hand layup and hot pressing. Firstly, the epoxy component (MR3010) was mixed with the hardener component (MH3124) for 4.5 min (3 times $1.5 \mathrm{~min}$; stirring, resting and stirring again) with an IKA RW16 mechanical stirrer. Three layers of carbon textile were infiltrated manually. Composite stacks were built up layer by layer in the alumina mould from the infiltrated carbon fibre layers. The composite was pressed in a Metal Fluid Engineering $30 \mathrm{~T}$ hydraulic hot press $\left(80^{\circ} \mathrm{C}, 100 \mathrm{bar}\right)$ for $20 \mathrm{~min}$ after mould closing. After pressing, the mould was cooled down to room temperature between closed press platens.

The main mechanical properties of CFRP, which may have a significant influence on the chip removal mechanisms of the composites, were determined with three-point bending, Charpy and Shore D hardness tests. Three-point bending tests were carried out according to the MSZ EN ISO 14125:1998/A1:2011 standard in a Zwick Z005 universal tensile machine on five specimens of each material. During the tests, crosshead speed was $10 \mathrm{~mm} / \mathrm{min}$, and support length was $64 \mathrm{~mm}$. The samples were tested until they broke completely. Charpy impact tests were performed according a)

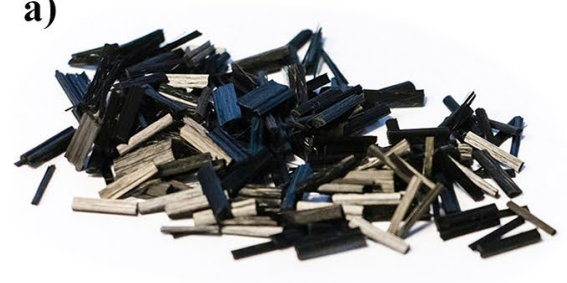

b)

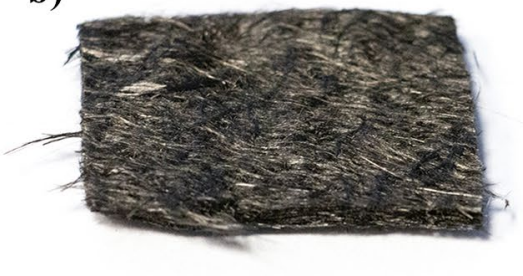

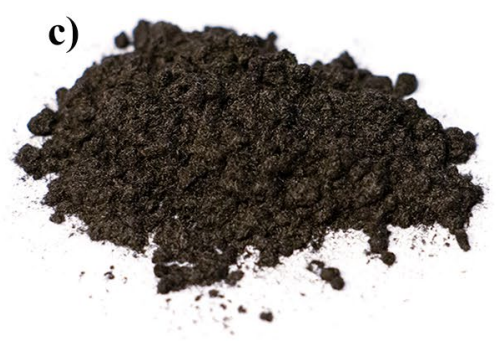

Fig. 1 The different structures of fibre reinforcements used: (a) chopped carbon fibres, (b) nonwoven mat and (c) milled carbon fibres 
Table 2 The main mechanical properties of the investigated CFRP composites

\begin{tabular}{lcllc}
\hline Code & $\begin{array}{l}\text { Flexural strength } \\
(\mathrm{MPa})\end{array}$ & $\begin{array}{l}\text { Flexural } \\
\text { modulus } \\
(\mathrm{GPa})\end{array}$ & $\begin{array}{l}\text { Charpy impact } \\
\text { strength }\left(\mathrm{kJ} / \mathrm{m}^{2}\right)\end{array}$ & $\begin{array}{l}\text { Shore D } \\
\text { hardness } \\
(-)\end{array}$ \\
\hline VA & $34.07 \pm 7.59$ & $2.85 \pm 0.29$ & $7.05 \pm 3.42$ & $73 \pm 10$ \\
VB & $74.17 \pm 2.53$ & $2.60 \pm 0.05$ & $0.86 \pm 0.17$ & $83 \pm 2$ \\
VC & $85.69 \pm 0.89$ & $5.06 \pm 0.21$ & $1.23 \pm 0.29$ & $86 \pm 2$ \\
RA & $32.21 \pm 5.09$ & $2.98 \pm 0.68$ & $3.06 \pm 0.93$ & $60 \pm 19$ \\
RB & $153.73 \pm 11.04$ & $6.75 \pm 0.36$ & $2.63 \pm 0.03$ & $86 \pm 1$ \\
RC & $104.78 \pm 5.46$ & $4.90 \pm 0.07$ & $1.22 \pm 0.39$ & $83 \pm 2$ \\
\hline
\end{tabular}

to the MSZ EN ISO 179-1:2010 standard with a Ceast Resil Impactor Junior with a $2 \mathrm{~J}$ hammer on five notched specimens of each material. The support length was $62 \mathrm{~mm}$, and the starting angle was $150^{\circ}$. Shore D hardness tests were carried out according to the MSZ EN ISO 868:2003 standard with a Zwick/Roell H04.3150.000 hardness tester. Every test was executed at room temperature and $45 \%$ relative humidity. The results of the tests are summarised in Table 2. The tensile properties of the specimens were not analysed, mainly because (i) the quasi-randomised orientation of single fibres of the applied non-unidirectional composites suggests a high inconsistency in the tensile properties, and (ii) the tensile properties have only a minor influence on the fibre fracture and chip removal mechanism in machining [15].

The diversity in the material properties of the tested CFRP composites suggested that their machinability would differ as well. Thus, the amount of drilling-induced burr and microstructure properties were expected to be significantly influenced by the reinforcement type and whether the carbon fibres were recycled or not.

\subsection{Machining environment}

The conventional drilling experiments were performed on a Kondia B640 CNC machine tool, equipped with a Nilfisk GB733 vacuum cleaner. The CFRP plates were fixed into a special drilling fixture, which fixed and supported the composites against buckling. The machining environmental setup is illustrated in Fig. 2.

Two types of uncoated solid carbide cutting tools were used for the drilling experiments: a THOMAS TDM $2 \mathrm{~L}$ 23C110100 special brad and spur drill (T1) and a THOMAS TDM 2L 23C100100 fishtail twist drill (T2). The inner part of $\mathrm{T} 1$ is like a double-point angle drill. The diameter of both cutting tools is $d=\varnothing 10 \mathrm{~mm}$ and they have advantageous geometrical features ("cut first, push second" effect), which may increase the quality of holes in CFRP: T1 has a clearance angle of $\alpha=6.7^{\circ} \pm \delta^{\circ}$ ( $\delta$ denotes the error of optical measurement) and a rake angle of $\gamma=30^{\circ} \pm \delta^{\circ}$, and
Fig. 2 Schematic drawings of the experimental setup and the applied cutting tools: (a) cutting machine tool, a special fixture to support the composite against buckling and an industrial vacuum cleaner; (b) T1 - brad and spur drill; (c) $\mathrm{T} 2$ - fishtail twist drill; and (d) digital microscopy and (e) scanning electron microscopy to analyse drilling-induced macro and microsized geometrical defects, respectively; (f) location of tool wear and tool geometry measurements
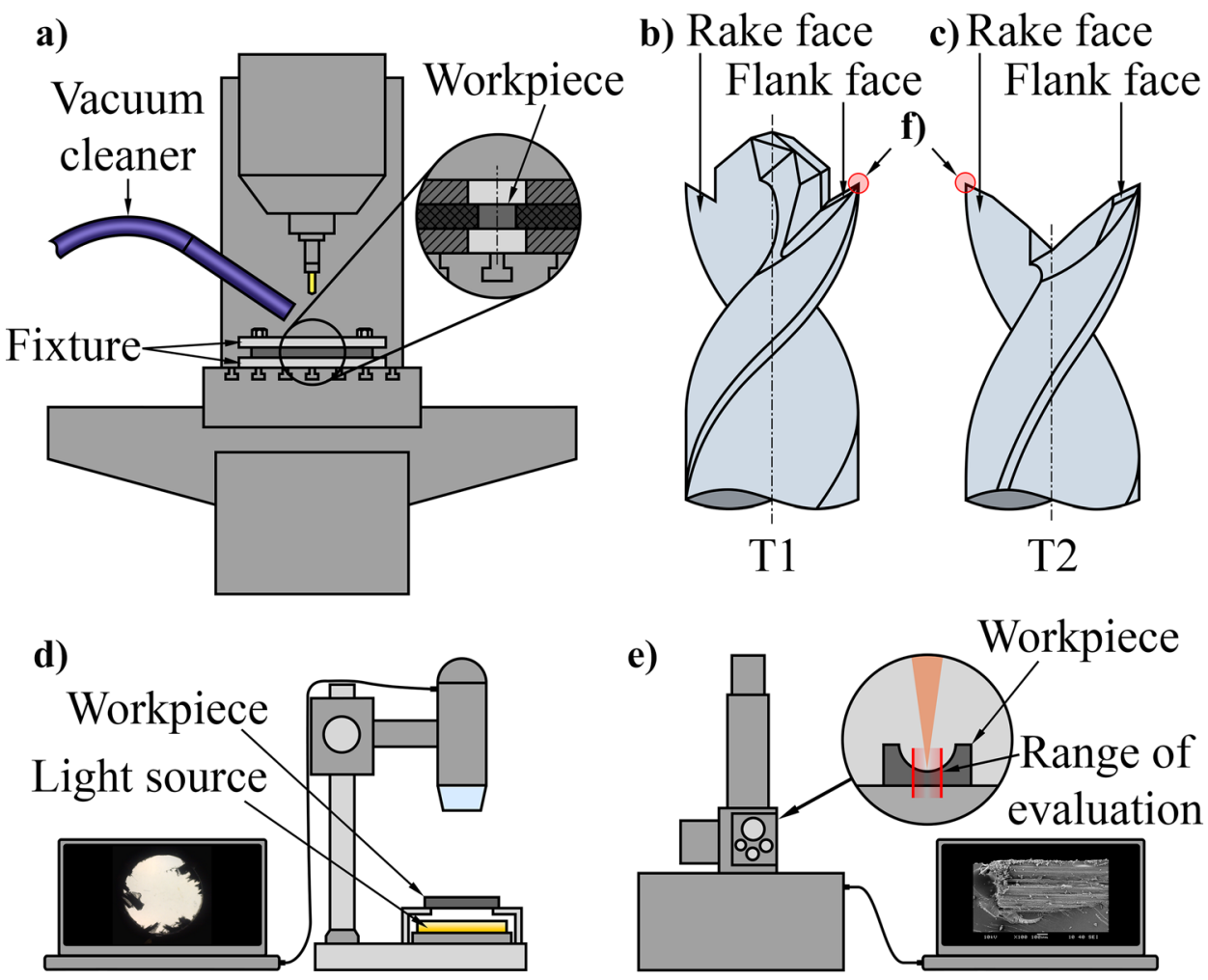
those angles of T2 are $\alpha=14^{\circ} \pm \delta^{\circ}$ and $\gamma=30^{\circ} \pm \delta^{\circ}$, respectively. The clearance and rake angles were measured at the outer diameter of the tools, where the cutting edge produces the final surface (Fig. 2f). Tool geometries are illustrated in Fig. 2. According to the tool producer's suggestions and the authors' experience, cutting speed was fixed to $v_{c}=100 \mathrm{~m} /$ $\min (3183 \mathrm{rpm})$, and the feed was set on three levels between $f_{\text {min }}=0.15$ and $f_{\text {max }}=0.35 \mathrm{~mm} / \mathrm{rev}$.

The levels and number of drilling experiments were designed based on the full factorial design, due to the unknown significance levels of the interaction effects of the input parameters. The factors and their levels (see in Table 3) were set based on previous studies and the experience of the authors in the machinability of virgin CFRP [35, 39-41]. The experiments were repeated five times in each experimental setup and they were run in a randomised order. The total number of drilling experiments was 180 .

Machining-induced macro-sized geometrical defects (e.g. burrs, tearing) were analysed by optical microscopy, and the microsized geometrical defects (e.g. fibre pull-out, matrix smearing, micro-cracks) were analysed by scanning electron microscopy. A Dino-Lite AM413TL digital microscope (with a resolution of 1.3 megapixels and a magnification of $\times 20$ ) was used for capturing digital images of drilled holes. The images were processed by digital image processing (DIP) tools, e.g. contrast increase, edge detection, segmenting and pixel counting. In this study, drilling-induced burr is numerically characterised with the burr factor $\left(F_{b}\right)$ and the contour burr factor $\left(F_{b c}\right)$, expressed by Eq. (1) and (2), respectively.

$F_{b}=\frac{A_{b}}{A_{\text {nom }}} \cdot 100=\frac{A_{\text {nom }}-A_{\text {free }}}{A_{\text {nom }}} \cdot 100$

$F_{b c}=\frac{C_{b}-C_{n o m}}{C_{n o m}} \cdot 100$

where $F_{b}(\%)$ denotes the burr factor, $A_{b}\left(\mathrm{~mm}^{2}\right)$ is the burr area, $A_{\text {nom }}\left(\mathrm{mm}^{2}\right)$ is the area of the nominal (ideal) hole, $A_{\text {free }}$ $\left(\mathrm{mm}^{2}\right)$ is the area of the burr-free area of the hole, $F_{b c}(\%)$ is the contour burr factor, $C_{b}(\mathrm{~mm})$ is the contour length of the burr and $C_{n o m}(\mathrm{~mm})$ is the contour length of a nominal hole, as illustrated in Fig. 3. The larger the values of $F_{b}$ and $F_{b c}$, the more significant the appearance of machining-induced

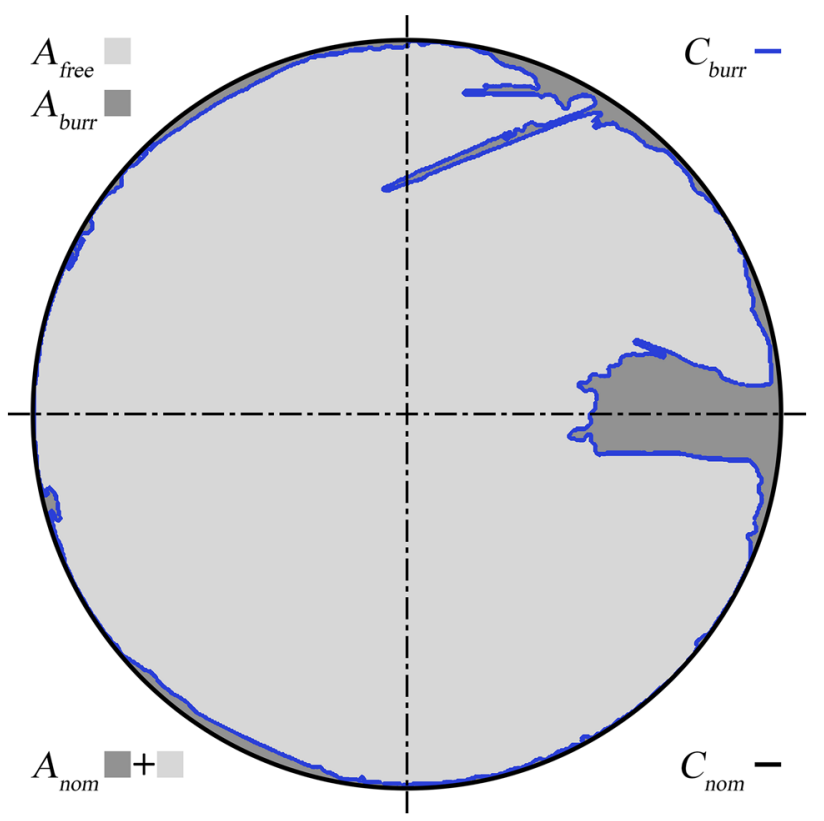

Fig. 3 A schematic illustration of drilling-induced burrs and their characteristics

burrs. The microstructure of the machined geometrical features of CFRP was analysed with a JEOL JSM 6380LA scanning electron microscope (SEM). An accelerating voltage of $10 \mathrm{kV}$ and a spot size of 40 was set. A JEOL JFC1200 fine coater machine coated the surfaces of the samples.

\section{Results and discussion}

Experimental results of drilling-induced micro-sized and macro-sized geometrical defects are presented and discussed in this section. According to recent studies on chip removal and burr formation mechanisms, the formation of geometrical defects is significantly influenced by the wear status of the applied cutting tools $[42,43]$. Cutting edge rounding is the main form of wear of cutting tools when cutting carbon fibre-reinforced composites; therefore, the size of the cutting edge radius was monitored during the experiments. A digital image of the cutting edge at the outer diameter of the tools was captured after each experimental setup. Besides

Table 3 Factors and their levels

\begin{tabular}{|c|c|c|c|c|c|c|c|c|}
\hline \multirow[t]{2}{*}{ Factors } & & & \multicolumn{3}{|c|}{ Levels } & \multirow[b]{2}{*}{4} & \multirow[b]{2}{*}{5} & \multirow[b]{2}{*}{6} \\
\hline & & & 1 & 2 & 3 & & & \\
\hline Tool geometry & $T$ & - & $\mathrm{T} 1$ & $\mathrm{~T} 2$ & & & & \\
\hline Feed & $f$ & $\mathrm{~mm} / \mathrm{rev}$ & 0.15 & 0.25 & 0.35 & & & \\
\hline Material & $M$ & - & VA & VB & $\mathrm{VC}$ & RA & $\mathrm{RB}$ & $\mathrm{RC}$ \\
\hline
\end{tabular}



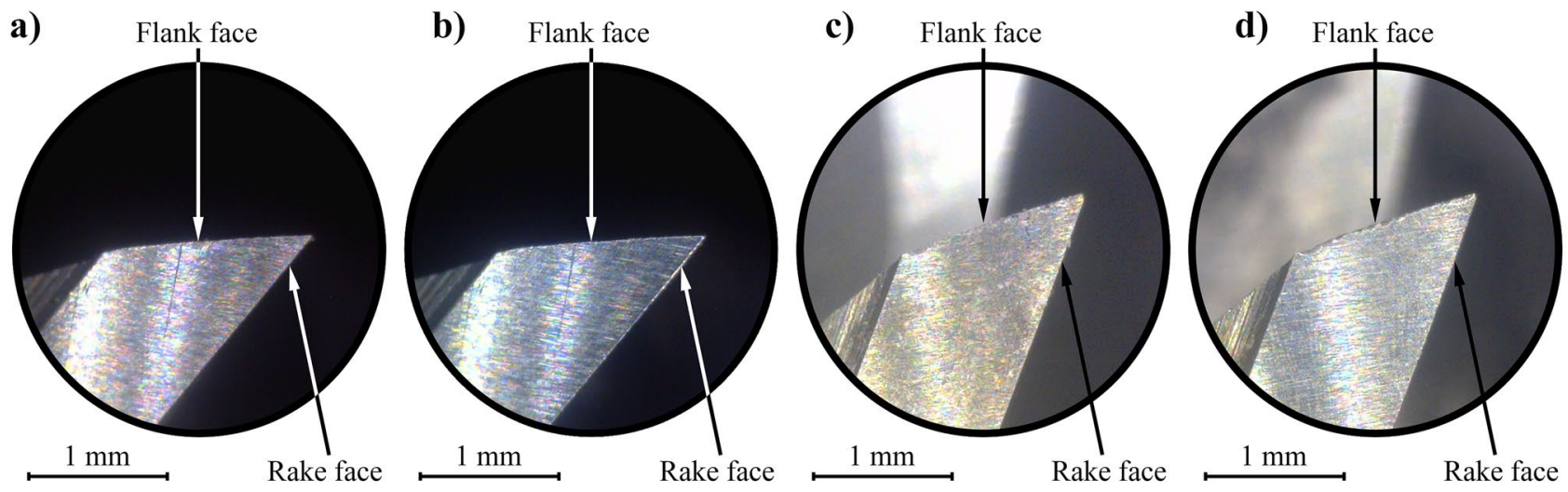

Fig. 4 Tool conditions: T2 drilling tool (a) before the 1st experimental run, (b) after the last (90th) experimental run, and T1 drilling tool (c) before the 1 st experimental run, $(\mathbf{d})$ after the last $\left(90^{\text {th }}\right)$ experimental run

that, tool wear was unexpected due to the proper selection of tool material (solid carbide); measurements proved it. The cutting edge radius of the applied cutting tools can be seen in Fig. 4. The results prove that tool wear is negligible; the results of drilling-induced burrs and microstructures do not therefore have to be compensated for.

\subsection{Drilling-induced burrs}

Drilling-induced burrs were characterised in this study by the burr factor $\left(F_{b}\right)$ and the contour burr factor $\left(F_{b c}\right)$. Each parameter was calculated by digital image processing (DIP) of images of the exits of holes. While the burr factor correlates with the specific area of machining-induced burr, the contour burr factor correlates with the specific length of the contour of the damaged area. The latter may provide indirect but quantitative information on the level of destruction of the uncut composite [27]. Representative processed images of burrs are shown in Fig. 5.

The influences of the selected independent variables (feed, tool and material) on the response variables $\left(F_{b}\right.$ and $F_{b c}$ ) were analysed by means of analysis of variance (ANOVA) at a significance level of $p=0.05$. The main effects of the factors on the burr factor $\left(F_{b}\right)$ can be seen in Fig. 6, and their dominancy and significance are shown by the ANOVA tables in Tables 4 and 5. The ANOVA results show that the influence of the material is significant on both the $F_{b}$ and $F_{b c}$ parameters. The burr factors of drilled holes in the composite reinforced by virgin chopped carbon fibres (VA) were the most substantial, followed by those of polymer composites reinforced by recycled chopped carbon fibres (RA), virgin nonwoven mats (VB), recycled milled carbon fibres (RC), virgin milled carbon fibres $(\mathrm{VC})$ and recycled nonwoven mats $(\mathrm{RB})$. The impregnation homogeneity of the CFRP reinforced by the chopped fibres was possibly not as good as that of the CFRP reinforced by the milled fibres and nonwoven mats; therefore, the fibres were not appropriately supported against buckling, which resulted in more burrs. It is discussed later when the microstructure of the machined surfaces is analysed in Sect. 3.2

For composites reinforced with chopped carbon fibres (A) and nonwoven mats (B), the burr factors of drilled holes in virgin CFRP are definitely higher than in rCFRP. That may suggest that recycling has a measurable influence on drilling-induced burr.

According to the ANOVA tables and the main effect plots, the influence of the cutting tool on both the $F_{b}$ and $F_{b c}$ parameters is significant. Figure 6 shows that T1 produced significantly more drilling-induced burrs than $\mathrm{T} 2$. Even though the brad and spur geometries are favourable for burr removal due to their "cut first, push second" effect, the fishtail drill produced fewer burrs. Although the outer (primary) cutting geometries of the tools are similar, the inner cutting geometries of the tools significantly differ. The outer edges of T2 cut the last "layers" first, rather than an inner edge. Therefore, the fishtail drills are recommended for drilling high-quality holes in each analysed reinforced composite structure.

The ANOVA results show that the influence of feed is not significant on the burr factor. Even though the effect of feed on cutting force (and thus on delamination) is already widely studied and well known [14] (the larger the feed is, the larger the chip cross-section is, and the larger the cutting force is, therefore, the larger the probability of delamination is), the effect of feed on burr formation is not evident. Our results show that neither the burr factor nor the contour burr factor is influenced significantly by feed; thus, from the point of view of burr minimization, 


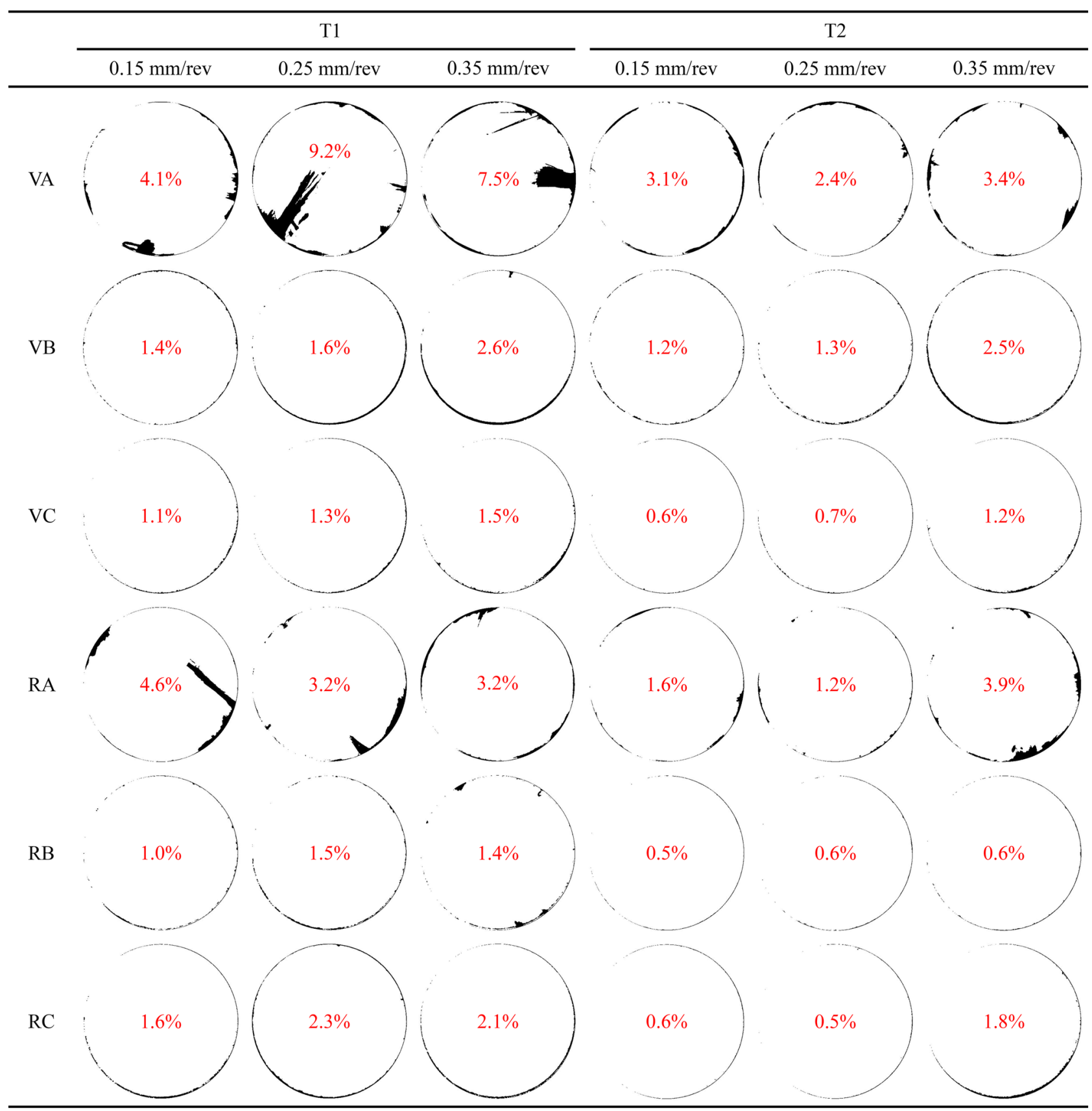

Fig. 5 Representative images of drilling-induced burrs on the exit edges of the holes (The red values inside the holes represent the burr factor)

maximum feed is recommended to maximise the material removal rate (MRR).

The interaction plot in Fig. 7 shows that the interaction terms are significant only when the tool and material are concerned. Although the interaction of tool and material is statistically significant, $\mathrm{T} 2$ produced fewer burrs than $\mathrm{T} 1$ in each case. The other two-way and three-way interactions are negligible, as the ANOVA results show in Tables 4 and 5.
The correlation between the burr factor $\left(F_{b}\right)$ and contour burr factor $\left(F_{b c}\right)$ can be seen in Fig. 8 and Fig. 9. $F_{b}$ correlates with $F_{b c}$ in virgin, and recycled chopped carbon fibre-reinforced composites. It means that the higher $F_{b}$ is, the higher $F_{b c}$ is. This may suggest that the more burrs there are, the more significant the damage to the uncut composite is in VA and RA composites. This observation may be explained by the fact that the cutting tool gets into contact 
Fig. 6 Main effect plots for the burr factor $\left(F_{b}\right)$ at a significance level of $p=0.05$

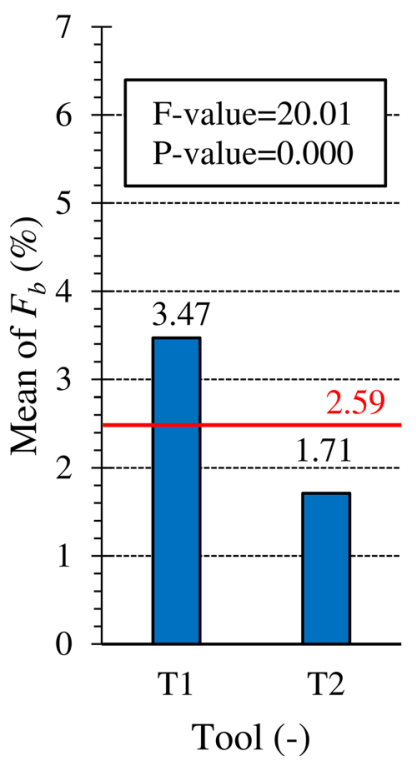

with the fibres (and slides and abrades the fibres) more often if the (final) burr is longer; thus, the uncut composite is expected to be more damaged if the burr is longer. As long as burr length is proportional to the specific burr area, the amount of damage to the uncut composite is expected to correlate to $F_{b c}$.

Despite the observation that $F_{b}$ correlates with $F_{b c}$ in virgin and recycled chopped carbon-reinforced polymer composites, there was no linear correlation between milled carbon fibres and nonwoven mats, as illustrated in Fig. 9. Positions of the grouped data points in Fig. 9a suggest that

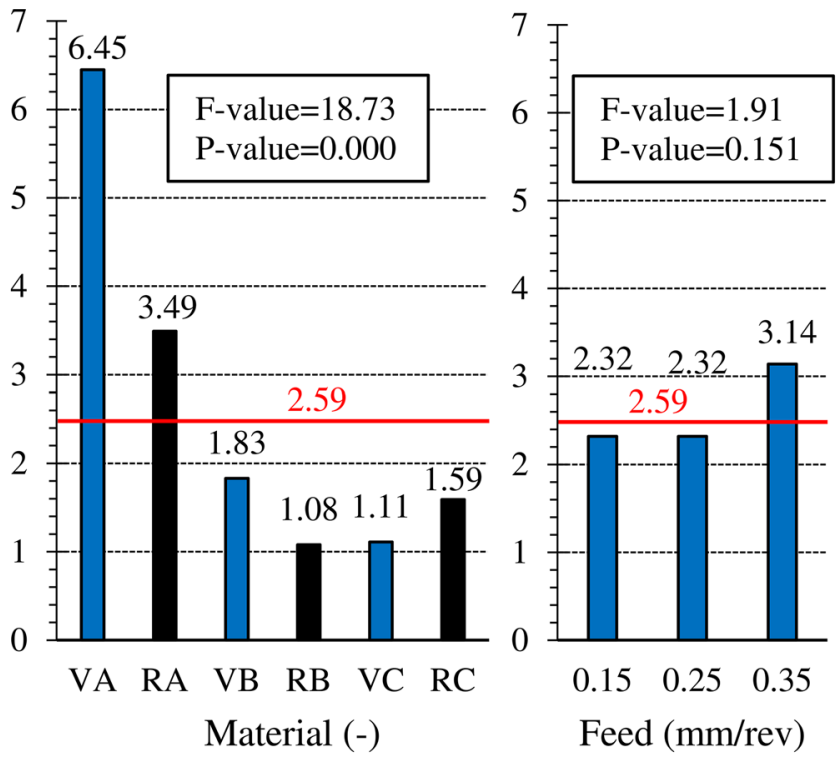

the ranges of burr factors are similar: $F_{b, V B}=1.18-2.61 \%$ and $F_{b, R B}=0.84-2.46 \%$ in the case of T1, and $F_{b, V B}=0.73-2.84 \%$ and $F_{b, R B}=0.54-1.54 \%$ in the case of T2. However, the characteristic ranges of contour burr factors differ significantly: $F_{b c, V B}=11.17-16.47 \%$ and $F_{b c, R B}=14.14-41.24 \%$ in the case of T1, and $F_{b, V B}=13.04-29.45 \%$ and $F_{b, R B}=10.48-16.96 \%$ in the case of T2. This diversity in the ranges of $F_{b c}$ suggests that burr formation should be characterised based on both burr indicators rather than only on $F_{b}$. The results also suggest that the cutting tool has the most significant influence on the location groups, and the material has the most

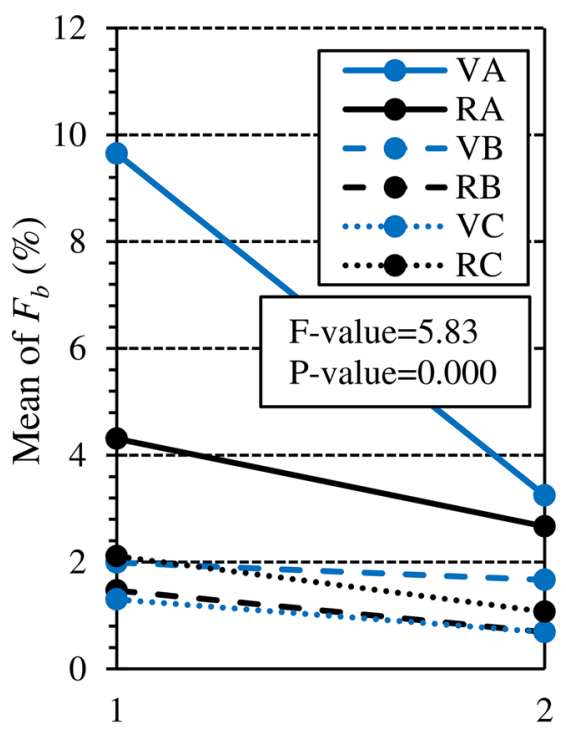

Tool (-)
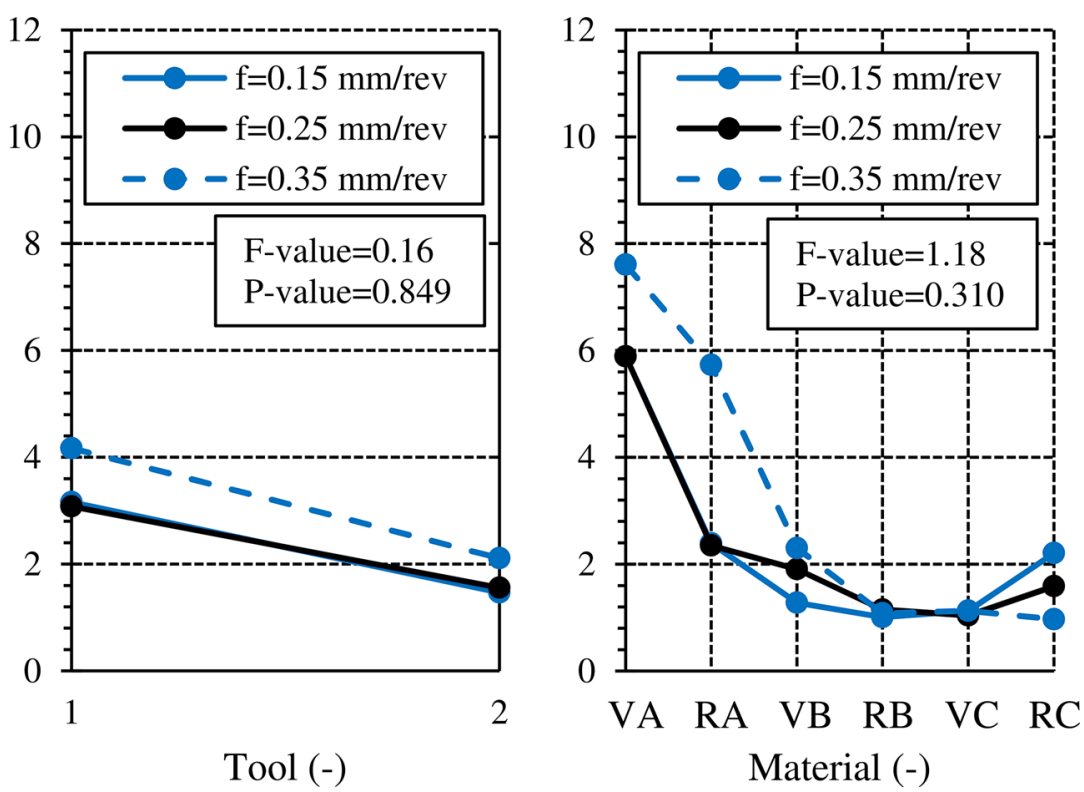

Fig. 7 Interaction plots for the burr factor $\left(F_{b}\right)$ at a significance level of $p=0.05$ 
Table 4 The analysis of variance (ANOVA) table for the burr factor $\left(F_{b}\right)$

\begin{tabular}{llrrrr}
\hline Source & DF & \multicolumn{1}{c}{ Adj SS } & Adj MS & $F$-value & $P$-value \\
\hline Model & 35 & 1142.28 & 32.636 & 4.69 & 0.000 \\
Linear & 8 & 817.82 & 102.227 & 14.69 & 0.000 \\
$T(-)$ & 1 & 139.25 & 139.245 & 20.01 & 0.000 \\
$M(-)$ & 5 & 651.92 & 130.385 & 18.73 & 0.000 \\
$f(\mathrm{~mm} / \mathrm{rev})$ & 2 & 26.65 & 13.325 & 1.91 & 0.151 \\
2-way interactions & 17 & 287.18 & 16.893 & 2.43 & 0.002 \\
$T \cdot M$ & 5 & 202.83 & 40.566 & 5.83 & 0.000 \\
$T \cdot f$ & 2 & 2.28 & 1.140 & 0.16 & 0.849 \\
$M \cdot f$ & 10 & 82.07 & 8.207 & 1.18 & 0.310 \\
3-way interactions & 10 & 37.28 & 3.728 & 0.54 & 0.863 \\
$T \cdot M \cdot f$ & 10 & 37.28 & 3.728 & 0.54 & 0.863 \\
Error & 144 & 1002.17 & 6.960 & & \\
Total & 179 & 2144.45 & & & \\
\hline
\end{tabular}

significant effect on the deviation of burr characteristics. Figure $9 \mathrm{~b}$ shows, similarly to Fig. 9a, that the diversity in $F_{b c}$ is significant compared to $F_{b}$. Furthermore, the deviation of burr characteristics was the greatest in composites reinforced with recycled milled carbon fibres and a recycled nonwoven mat when the $\mathrm{T} 1$ tool was used.

\subsection{The microstructure of machined holes}

Machined surfaces of CFRP composites can be analysed through surface roughness analysis by contact or non-contact methods; however, these results usually provide only indirect information about surface quality and machining-induced critical material failures. In fibrous polymer composites,

Table 5 The analysis of variance (ANOVA) table for the contour burr factor $\left(F_{b c}\right)$

\begin{tabular}{lllrrl}
\hline Source & DF & Adj SS & Adj MS & F-value & P-value \\
\hline Model & 35 & 60,138 & 1718.22 & 4.85 & 0.000 \\
Linear & 8 & 41,140 & 5142.53 & 14.51 & 0.000 \\
$T(-)$ & 1 & 5305 & 5305.16 & 14.97 & 0.000 \\
$M(-)$ & 5 & 34,647 & 6929.49 & 19.56 & 0.000 \\
$f(\mathrm{~mm} / \mathrm{rev})$ & 2 & 1188 & 593.79 & 1.68 & 0.191 \\
2-way interactions & 17 & 17,089 & 1005.22 & 2.84 & 0.000 \\
$T \cdot M$ & 5 & 14,368 & 2873.69 & 8.11 & 0.000 \\
$T \cdot f$ & 2 & 193 & 96.55 & 0.27 & 0.762 \\
$M \cdot f$ & 10 & 2527 & 252.72 & 0.71 & 0.711 \\
3-way interactions & 10 & 1909 & 190.87 & 0.54 & 0.860 \\
$T \cdot M \cdot f$ & 10 & 1909 & 190.87 & 0.54 & 0.860 \\
Error & 144 & 51,025 & 354.34 & & \\
Total & 179 & 111,163 & & & \\
\hline
\end{tabular}

machining-induced fracture mechanisms are dominated by the fracture of fibres (mainly bending, but often shear or tensile-induced) and fibre-matrix debonding [44]. These critical failures and other typical microsized geometrical material defects (e.g. fibre pull-outs, matrix smearing, voids, micro-cracks) in virgin and recycled CFRP were examined by scanning electron microscopy (SEM), as illustrated in Fig. 2e. Even though it is well known that burr formation and crack propagation are significantly influenced by the fibre cutting angle $(\theta-$ the angle between the direction of cutting speed and fibre orientation [15]), the location of machining-induced defects was difficult to determine, because the applied nonunidirectional reinforcement structures and CFRP manufacturing technologies resulted in a quasi-randomised orientation of single fibres.

Figure 10 shows representative SEM images of drilled hole surfaces in polymer composites reinforced with virgin and recycled chopped carbon fibres. Typical fibre pull-outs (e.g. Figure 10i), voids (e.g. Figure 10k) and non-homogeneous impregnation quality (Fig. 10e and f) were observed, which might have caused the previously discussed significant burr in RA and VA composites. The pre-manufacturing process (compression moulding) and the mechanical drilling-induced voids-regardless of whether they are material discontinuities due to improper impregnation or drilling-induced fibre pull-outs-failed to support the fibre reinforcements against buckling. If the fibres were not supported properly, they got buckled by the cutting tool and a considerable uncut composite appeared even with properly selected cutting tool geometry and process parameters. More significant fibre pull-out was observed in the virgin CFRP, which may mean that burr formation is more significant in virgin CFRP than in rCFRP. Machining-induced fibre pull-outs can be seen in (Fig. 10h), and fibre group pull-outs can be seen in (Fig. 10b and j) in virgin and recycled CFRP, respectively.

Figure 10d and its upscaled images (Fig. 10e and f) illustrate the impregnation inhomogeneity of the composites. Even though the CFRP were manufactured with the use of a highly automated and precise technology, the epoxy resin could not penetrate the inner fibre groups (Fig. 10f) effectively, as was observable in the outer fibre groups (Fig. 10e). Therefore, the difficulty of predicting the - not only fibre orientation-dependent-material properties of chopped fibre-reinforced composites is greater. In the future, a great effort is likely to be made to model the material defects and optimise the properties of virgin and recycled chopped CFRP.

Representative SEM images of the microstructure of machined surfaces of nonwoven mat carbon fibre-reinforced polymer composites (VB and RB) can be seen in Fig. 11. The carbon fibres are longer, and their orientations are not as random as those of chopped carbon fibres. Therefore, burrs 

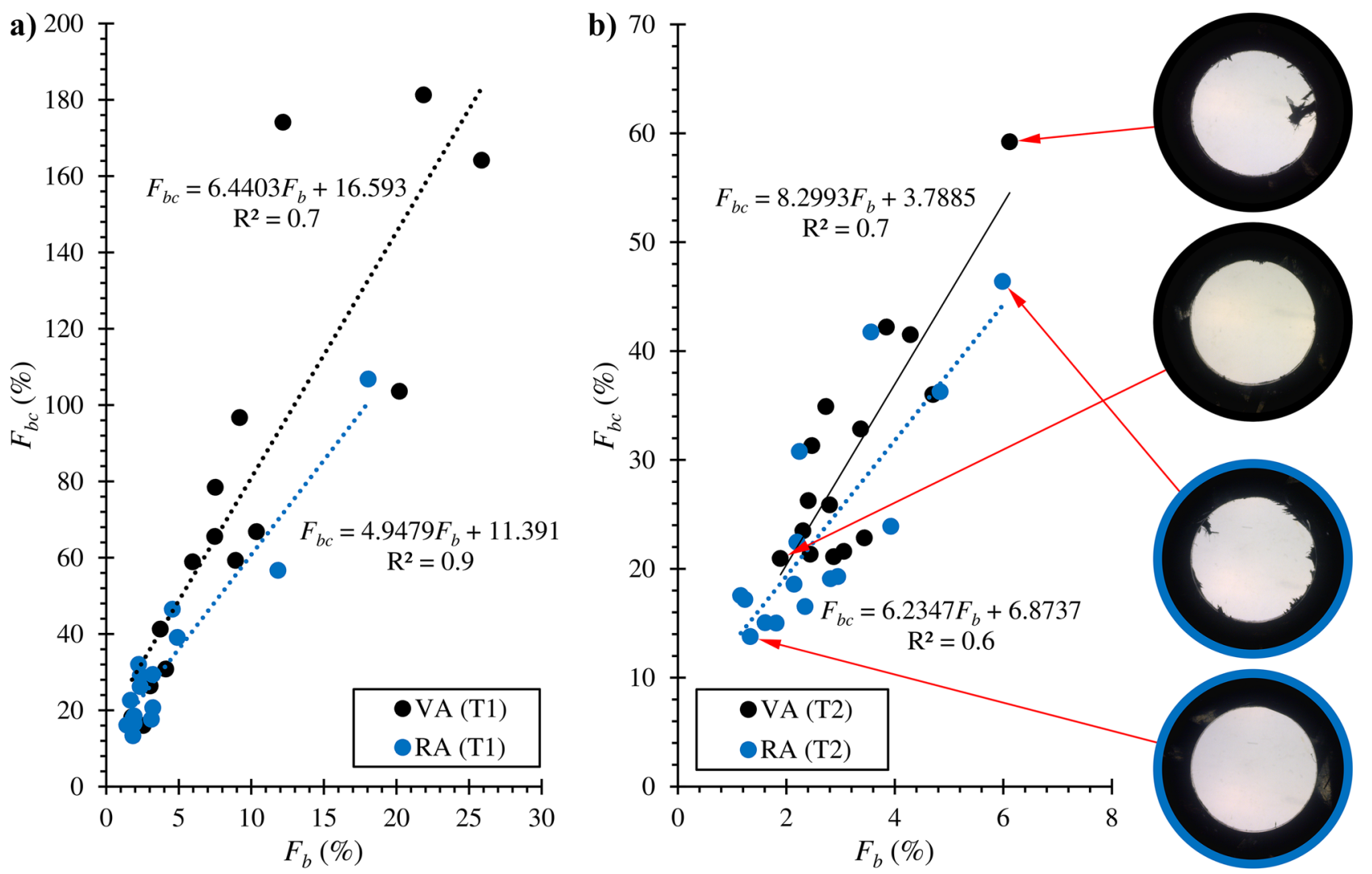

Fig. 8 The ratio of burr factor $\left(F_{b}\right)$ and contour burr factor $\left(F_{b c}\right)$ in virgin and recycled chopped carbon-reinforced polymer composites when (a) the T1 brad and spur drill and (b) the T2 fishtail drill was used

and typical drilling-induced micro-sized geometrical defects are easier to predict. SEM images of the microstructure show that pull-out is not significant (Fig. 11d), and adhesion quality is good (e.g. Figure 11e); only significant matrix smearing was observed at each fibre cutting angle. In contrast to machined chopped CFRP, the marks of the cutting tool can be seen (Fig. 11a). The fractured ends of the carbon fibres are similar in virgin, and recycled composites: mostly tensile-dominated fibre fracture (e.g. Figure $11 \mathrm{c}$ and f) was observed in each location. Despite those observations that the surface is not free of material discontinuities (e.g. Figure 11e), the overall quality of the machined surface is good, resulting in less burr than in the case of chopped CFRP.

Representative SEM images of the microstructure of machined surfaces of milled carbon fibre-reinforced polymer composites (VC and RC) can be seen in Fig. 12. Mainly due to the short carbon fibres, the orientations of the reinforcements are randomised, which can be seen in the SEM images. In contrast to the previously discussed cases (A and B), there were almost no voids or significant perpendicular fibre pull-outs, resulting in reduced burr formation. The overall quality of the microstructure of both machined virgin and recycled milled carbon fibre-reinforced polymer composites is excellent. However, there were fibre pull-outs parallel to the machined surface (Fig. 12d, f and h). The feed motion (Fig. 12g) and the main cutting edge (Fig. 12j, $\mathrm{k}$ and $\mathrm{l}$ ) marked on the epoxy resin in the rCFRP resulted in significant matrix smearing. Significant matrix smearing may mask potential machining-induced defects (e.g. voids), according to Ashworth et al. [45].

Despite the significant matrix smearing, numerous broken fibres were observed. In most cases, breakage occurred perpendicularly to the longitudinal axis of the fibre (Fig. c, $\mathrm{j}$ and $\mathrm{k}$ ). These fibre fractures may have been caused by the compression effect of the cutting tool (caused by the cutting edge radius), which compressed the fibres in the radial direction. Although these fibre breakages result in lower resulting material strength, they may cause higher resulting energy absorption properties. The proper discussion of these phenomena will be a goal of further research we will carry out. 

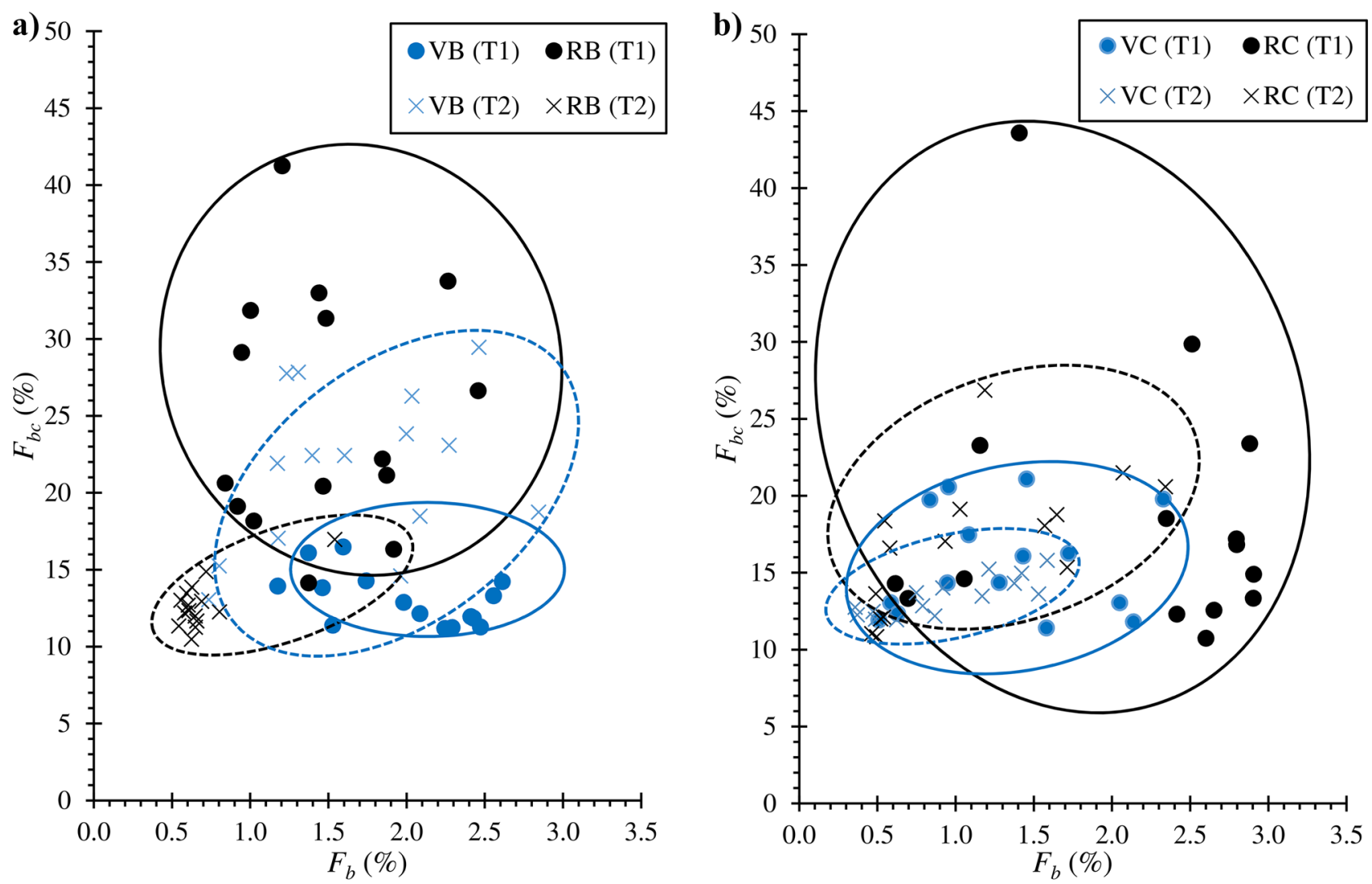

Fig. 9 The ratio of burr factor $\left(F_{b}\right)$ and contour burr factor $\left(F_{b c}\right)$ in (a) virgin and recycled nonwoven mat and in (b) milled carbon fibre-reinforced polymer composites

\subsection{Discussion and outlook}

Drilling-induced burr and SEM results indicate that the better the surface integrity (fewer voids and fibre pull-outs, better impregnation, etc.), the lower the probability of burr formation. This may be explained by the analysis of the quality of mechanical support of the reinforcing fibres (proper clamping of the composite, solid embedding of the fibres and tool geometry). The typical void-induced burr formations in fibrous composites are schematically illustrated in Fig. 13. As the highlighted fibre in Fig. 13a is supported against buckling — relative to the cutting motion—by a properly impregnated composite and adhesive matrix and other fibres, the probability of burr formation is expected to be low. Nevertheless, the less mechanical support the highlighted fibre has, the greater the probability of burr formation, based on the analogy of a buckling cantilever beam. The support of the highlighted fibre may be worse due to improper adhesion (Fig. 13b), inferior impregnation quality (Fig. 13c), single fibre pull-out (Fig. 13d) or pull-out of fibre groups (Fig. 13e). The fibre deflections ( $L$ ) caused by the lack of mechanical support are illustrated in Fig. 13. $L_{a}$ (fibre deflection in Fig. 13a) is expected to be the smallest, followed by $L_{b}$ and $L_{c}$, respectively. Furthermore, $L_{d}$ is expected to be smaller than $L_{e}$ because the larger the number of fibre pull-outs, the worse mechanical support is. Since larger fibre deflection means a greater probability of burr formation [29], the probability of burr formation is higher with worse mechanical support. Therefore, the burr and microstructure results seem to be consistent with the geometrical model illustrated in Fig. 13; however, the analytical description and model validation is required in the future.

The main results concerning the machining-induced burrs and micro-sized geometrical defects are consistent with each other. The present experimental data suggest that drillinginduced burr formation is less significant in chopped and nonwoven mat-reinforced rCFRP than polymer composites reinforced by virgin carbon fibres. Nevertheless, a proper report on the influence of recycling on burr formation needs a further detailed analysis of (i) the effect of the original 


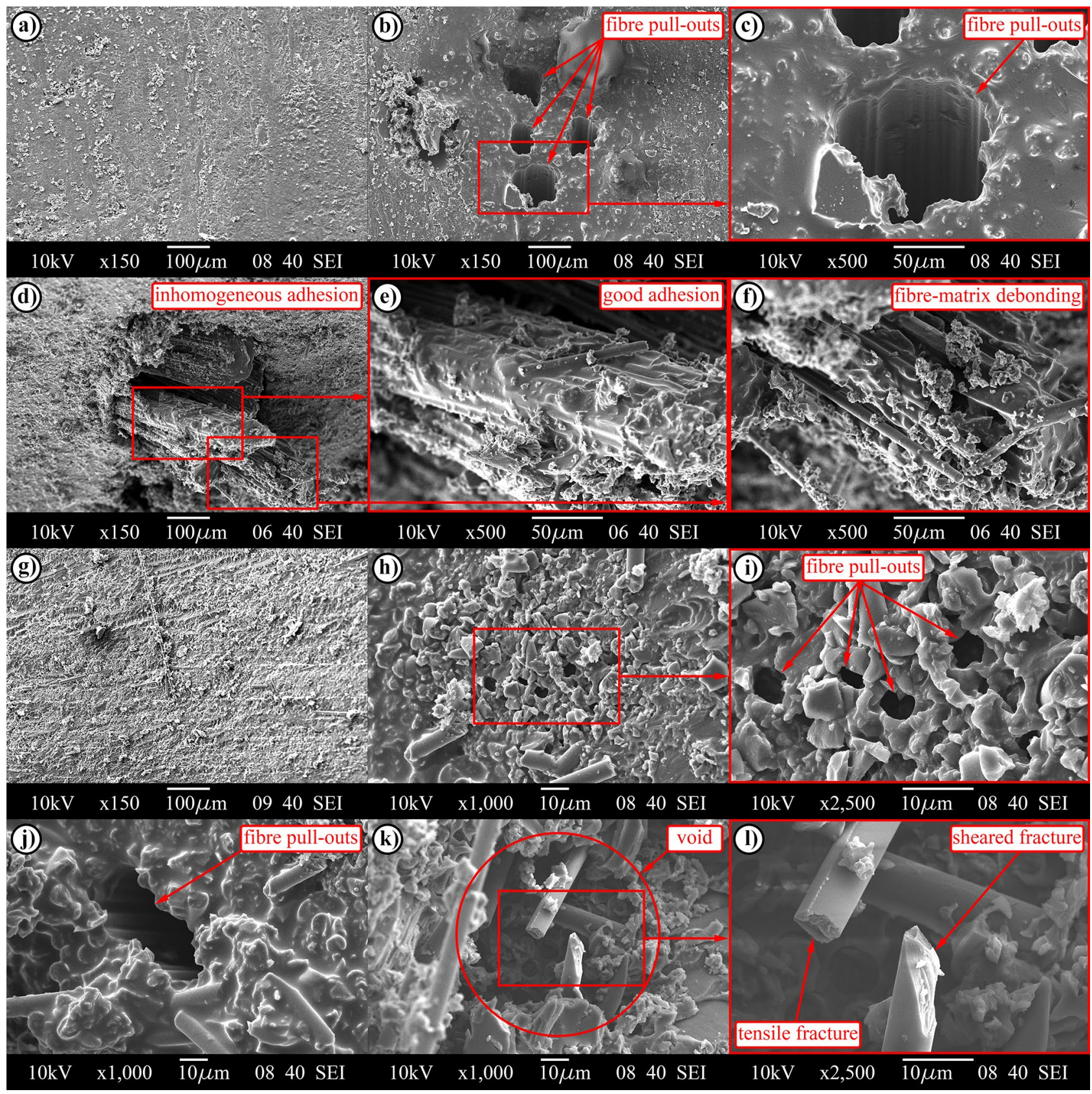

Fig. 10 SEM images of typical microsized geometrical defects in chopped CFR Ps: (a-f) virgin chopped CFRP composites and (g-l) recycled chopped CFRP composites

structure of the carbon fibres that are going to be recycled on the chemical and mechanical properties of rCFRP; (ii) the properties of sizing and the sizing technologies applied in rCFRP composite production; and (iii) the effect of the number of layers and fibre content in different reinforcing types on the properties of rCFRP. The authors suppose that the listed tasks will be highly time-consuming, costly and challenging, but this research and development work will be possibly decisive in the near future.

Although the experimental results showed that the burr characteristics of milled CFRP and rCFRP do not differ significantly, the possible future applications of milled rCFRP 


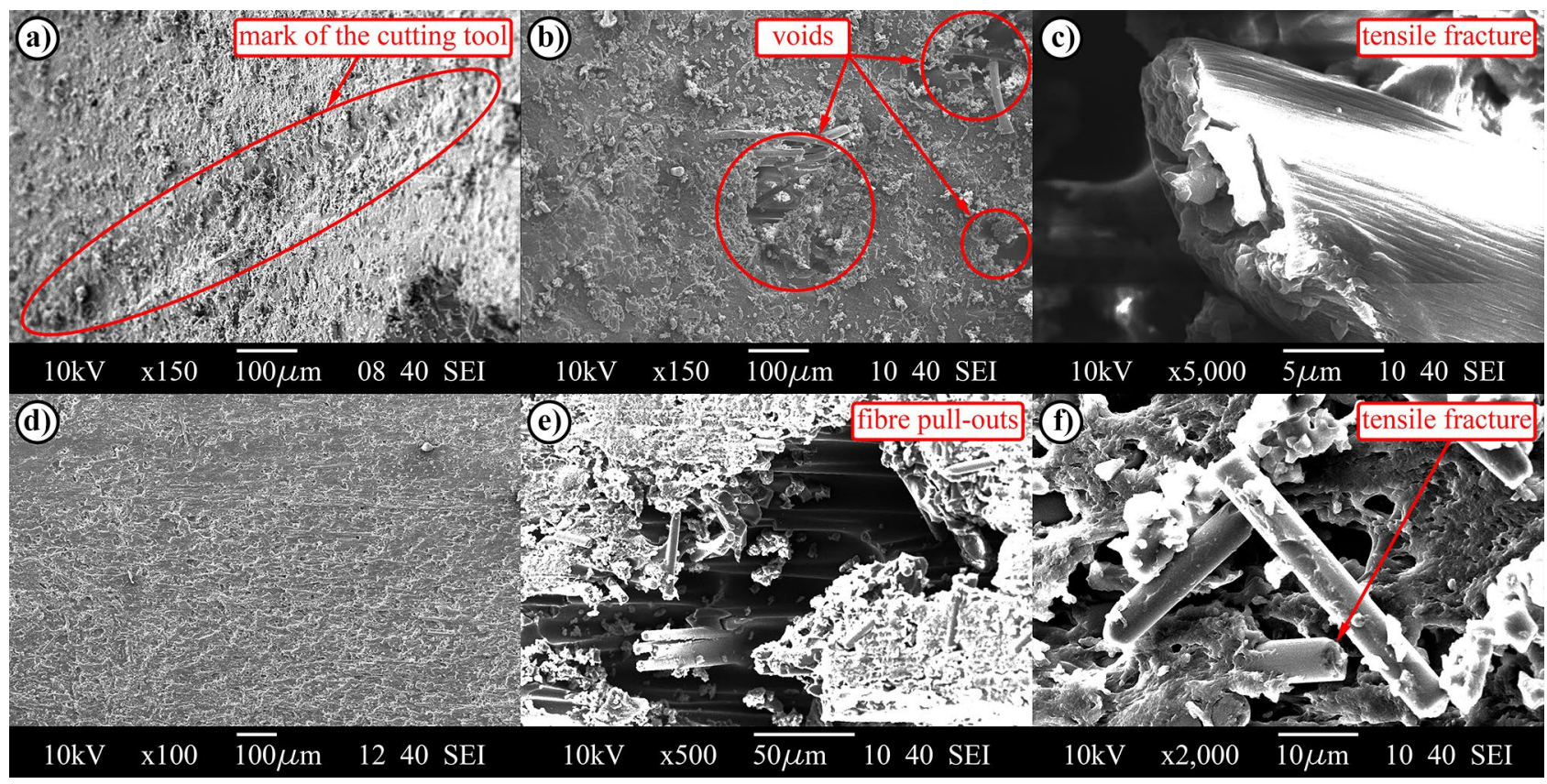

Fig. 11 SEM images of typical microsized geometrical defects in nonwoven mat CFR P: (a-c) virgin nonwoven mat CFRP composites and (d-f) recycled nonwoven mat CFRP composites

plates are not expected to be widespread, mainly because milled carbon fibres are often only used as fillers [46]. However, the present study suggests that the application of recycled milled carbon fibres as fillers in long fibre-reinforced polymer composites may not only have the general positive effects of fillers but also have a positive effect on machininginduced burr formation, too.

Since nonwoven mat rCFRP have high specific flexural strength and impact strength (Table 2), and their application decreases the ecological footprint (compared to virgin CFRP), these structures have a high potential in automotive, aerospace and marine applications. This study found no relevant objection against their application from the point of view of drilling-induced burrs and the microstructure damage of drilled surfaces.
Despite the present promising experimental results of drilling-induced burr and microstructure in virgin and recycled CFRP, many other important tests have to be performed in the future to show whether the machinability of rCFRP differs significantly from that of virgin CFRP, for example, (i) analysing and modelling chip removal mechanisms of rCFRP through orthogonal cutting experiments, (ii) analysing cutting force and the energy needed of cutting rCFRP, (iii) analysing the effect of sizing technologies ( adhesion quality) and layer properties on the machinability of rCFRP and (iv) machinability analysis of rCFRP, which focuses not only on recycled carbon fibres but also on recyclable engineering polymers (e.g. vitrimers [47]). 


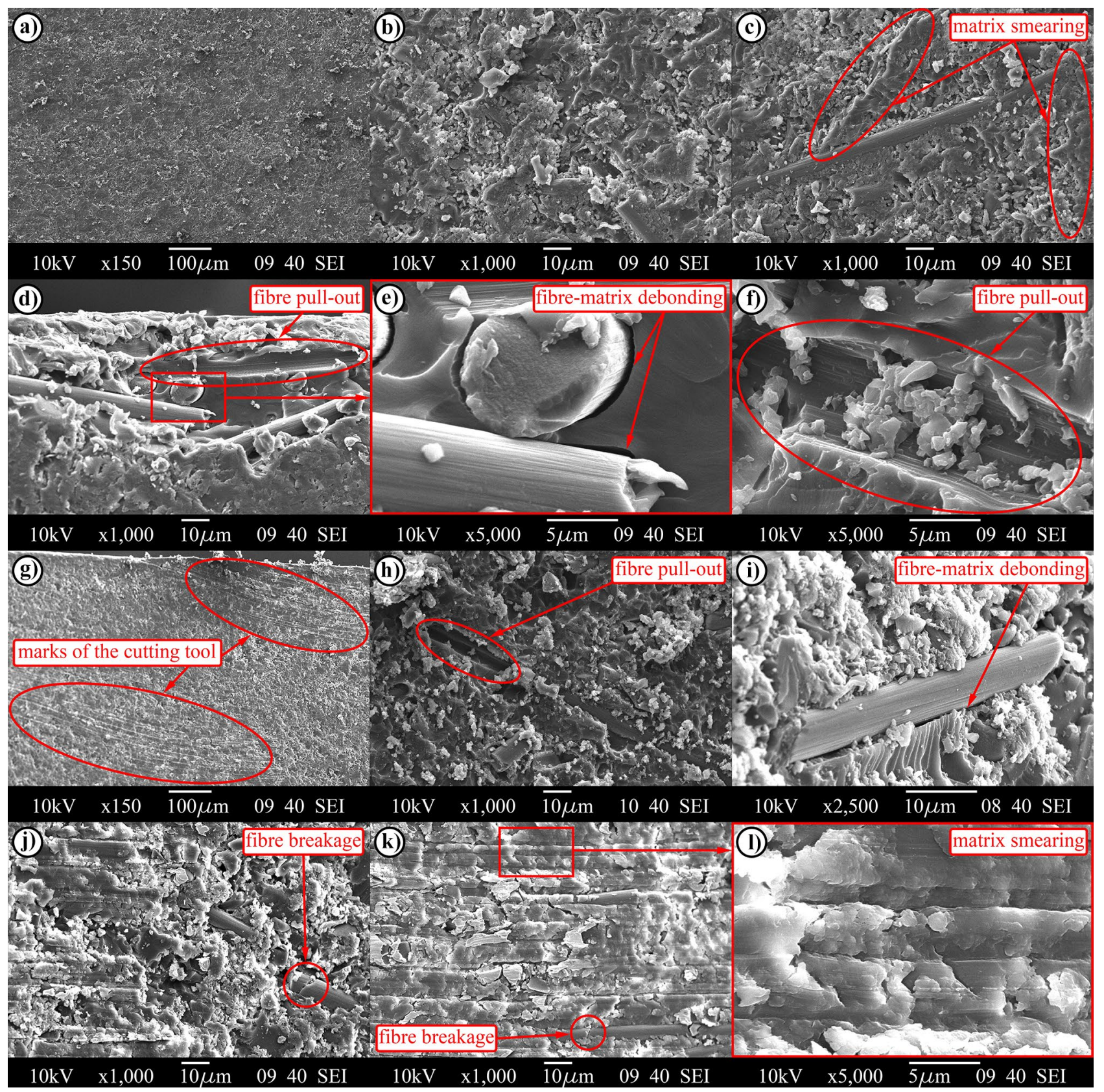

Fig. 12 SEM images of typical microsized geometrical defects in milled CFR Ps: (a-f) virgin milled CFRP composites and (g-l) recycled milled CFRP composites 


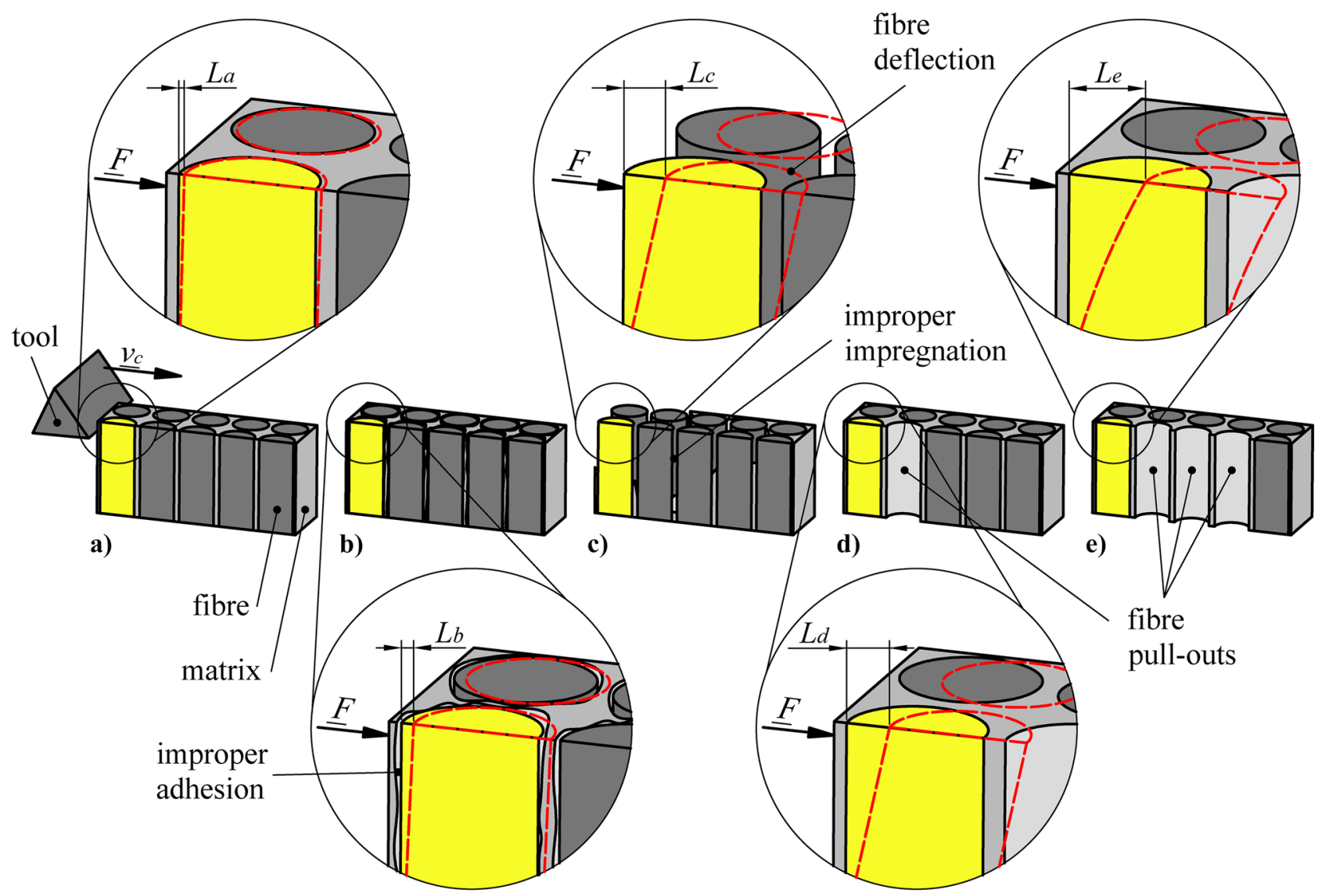

Fig. 13 The schematic illustration of burr formations in fibrous composites caused by void-induced buckling: (a) proper support of a single fibre, (b) improper adhesion caused reduced support of a single fibre, (c) improper impregnation results in weak support, (d) machining-induced pull-out of single fibre causes improper support and (e) machining-induced pull-out of fibre groups causes improper support

\section{Conclusions}

In the present study, drilling-induced micro- and macrosized geometrical defects were analysed and compared in virgin and recycled CFRP through optical and scanning electron microscopy. Based on the results of the present study, the following main conclusions can be drawn:

- The ANOVA results show that the composite material affects drilling-induced burr most, followed by the cutting tool. The influence of feed is statistically not significant; therefore-from the point of view of burr minimizationfeed is recommended to be maximised to increase material removal rate (MRR). Burr factors of virgin chopped CFRP composites were the highest, followed by those of recycled chopped CFRP, virgin nonwoven mat CFRP, recycled milled CFRP, virgin milled CFRP and recycled nonwoven mat CFRP. Burr formation in virgin CFRP was more pronounced than in chopped rCFRP and nonwoven mat rCFRP, which may be a general tendency.
- Significant fibre pull-outs, voids and non-homogeneous impregnation were observed through scanning electron microscopy in chopped carbon fibre-reinforced composites, which might have caused the significant burr. More fibre pull-outs were observed in virgin chopped CFRP than in recycled CFRP. Furthermore, pull-out was not significant in the case of the nonwoven mat CFRP, and the quality of adhesion was acceptable; only significant matrix smearing was observed with each fibre cutting angle.

- Considering drilling-induced burrs and microsized damage in carbon fibre-reinforced polymer composites, (i) the machinability of recycled nonwoven mat CFRP composites is the most advantageous, followed by that of virgin nonwoven mat CFRP, recycled chopped CFRP and virgin chopped CFRP; furthermore, (ii) the machinability of recycled milled and virgin milled carbon fibre-reinforced polymers do not differ significantly; and (iii) the fishtailtype drills are recommended for drilling high-quality holes in each analysed reinforced composite structure. 
- This study found no relevant objection against the future applications of rCFRP composites from the point of view of drilling-induced burrs and the microstructure damage of drilled surfaces. Nevertheless, the analysis of chip removal mechanisms, pre-manufacturing processes and the energy requirements of machining rCFRPs is recommended in the future to support the spread of recycled carbon applications.

Acknowledgements The authors acknowledge the support of Péter Sántha in the experimental work.

Author contribution Norbert Geier: conceptualization, methodology, writing —original draft, supervision; Dániel István POÓR: resources, formal analysis, investigation; Csongor Pereszlai: visualisation, software, writing — review and editing; Péter Tamás-Bényei: resources, writing — original draft.

Funding Open access funding provided by Budapest University of Technology and Economics. This research was partly supported by the National Research, Development and Innovation Office (NKFIH) No. OTKA-PD20-134430 and ÚNKP-21-5-BME-370 New National Excellence Program of the Ministry for Innovation and Technology, and by the János Bolyai Research Scholarship of the Hungarian Academy of Sciences No. BO/00658/21/6. The research reported in this paper and carried out at BME has been partly supported by the NRDI Fund (TKP2020 NC, Grant No. BME-NC) based on the charter of bolster issued by the NRDI Office under the auspices of the Ministry for Innovation and Technology and by the project "Centre of Excellence in Production Informatics and Control" (EPIC) No. EU H2020-WIDESPREAD-01-2016-2017-TeamingPhase2-739592.

\section{Declarations}

Ethics approval Not applicable.

Consent to participate Not applicable.

Consent for publication Not applicable.

Conflict of interest The authors declare no competing interests.

Open Access This article is licensed under a Creative Commons Attribution 4.0 International License, which permits use, sharing, adaptation, distribution and reproduction in any medium or format, as long as you give appropriate credit to the original author(s) and the source, provide a link to the Creative Commons licence, and indicate if changes were made. The images or other third party material in this article are included in the article's Creative Commons licence, unless indicated otherwise in a credit line to the material. If material is not included in the article's Creative Commons licence and your intended use is not permitted by statutory regulation or exceeds the permitted use, you will need to obtain permission directly from the copyright holder. To view a copy of this licence, visit http://creativecommons.org/licenses/by/4.0/.

\section{References}

1. Geier N, Paulo Davim J, Szalay T (2019) Advanced cutting tools and technologies for drilling carbon fibre reinforced polymer
(CFRP) composites: a review. Compos Part A 125:105552. https:// doi.org/10.1016/j.compositesa.2019.105552

2. Geier N, Szalay T, Takács M (2018) Analysis of thrust force and characteristics of uncut fibres at non-conventional oriented drilling of unidirectional carbon fibre-reinforced plastic (UD-CFRP) composite laminates. Int J Adv Manuf Technol 100:3139-3154. https://doi.org/10.1007/s00170-018-2895-8

3. Aamir M, Tolouei-Rad M, Giasin K, Nosrati A (2019) Recent advances in drilling of carbon fiber-reinforced polymers for aerospace applications: a review. Int J Adv Manuf Technol 105:2289_ 2308. https://doi.org/10.1007/s00170-019-04348-z

4. Karuppannan Gopalraj S, Kärki T (2020) A review on the recycling of waste carbon fibre/glass fibre-reinforced composites: fibre recovery, properties and life-cycle analysis. SN Appl Sci 2:433. https://doi.org/10.1007/s42452-020-2195-4

5. Pimenta S, Pinho ST (2011) Recycling carbon fibre reinforced polymers for structural applications: Technology review and market outlook. Waste Manag 31:378-392. https://doi.org/10.1016/j. wasman.2010.09.019

6. Okayasu M, Kondo Y (2018) Tensile properties of unsaturated polyester and epoxy resin reinforced with recycled carbon-fiberreinforced plastic. Appl Compos Mater 25:561-568. https://doi. org/10.1007/s10443-017-9635-3

7. Park J-M, Kwon D-J, Wang Z-J et al (2013) Effect of thermal treatment temperatures on the reinforcing and interfacial properties of recycled carbon fiber-phenolic composites. Compos Part Appl Sci Manuf 47:156-164. https://doi.org/10.1016/j.compositesa.2012.12.002

8. Rademacker T, Fette M, Jüptner G (2018) Sustainable use of carbon fibers through CFRP recycling. Lightweight Des Worldw 11:12-19. https://doi.org/10.1007/s41777-018-0041-9

9. Hadigheh SA, Wei Y, Kashi S (2021) Optimisation of CFRP composite recycling process based on energy consumption, kinetic behaviour and thermal degradation mechanism of recycled carbon fibre. J Clean Prod 292:125994. https://doi.org/10.1016/j.jclepro. 2021.125994

10. Zhao Q, Jiang J, Li C, Li Y (2020) Efficient recycling of carbon fibers from amine-cured CFRP composites under facile condition. Polym Degrad Stab 179:109268. https://doi.org/10.1016/j.polymdegradstab. 2020.109268

11. Genna S, Papa I, Lopresto V, Tagliaferri V (2020) Mechanical characterisation of CFRP laminates with recycled carbon fiber obtained by resin infusion under Flexible Tooling (RIFT) technology. Compos Sci Technol 199:108328. https://doi.org/10.1016/j. compscitech.2020.108328

12. Caggiano A, Centobelli P, Nele L, Teti R (2017) Multiple sensor monitoring in drilling of CFRP/CFRP stacks for cognitive tool wear prediction and product quality assessment. Procedia CIRP 62:3-8. https://doi.org/10.1016/j.procir.2017.03.047

13. Lin SC, Chen IK (1996) Drilling carbon fiber-reinforced composite material at high speed. Wear 194:156-162. https://doi. org/10.1016/0043-1648(95)06831-7

14. Xu J, An Q, Chen M (2014) A comparative evaluation of polycrystalline diamond drills in drilling high-strength $\mathrm{T} 800 \mathrm{~S} / 250 \mathrm{~F}$ CFRP. Compos Struct 117:71-82. https://doi.org/10.1016/j. compstruct.2014.06.034

15. Ahmad J (2009) Machining of polymer composites. Springer, US

16. Balázs BZ, Takács M (2018) Finite element modelling of thin chip removal process. IOP Conf Ser Mater Sci Eng 426:012002. https://doi.org/10.1088/1757-899X/426/1/012002

17. $\mathrm{Li} \mathrm{H}, \mathrm{Qin} \mathrm{X}, \mathrm{He} \mathrm{G}$ et al (2016) Investigation of chip formation and fracture toughness in orthogonal cutting of UD-CFRP. Int J Adv Manuf Technol 82:1079-1088. https://doi.org/10.1007/ s00170-015-7471-x

18. Molnar TG, Berezvai S, Kiss AK et al (2019) Experimental investigation of dynamic chip formation in orthogonal cutting. 
Int J Mach Tools Manuf 145:103429. https://doi.org/10.1016/j. ijmachtools.2019.103429

19. Xu J, Li C, Mi S et al (2018) Study of drilling-induced defects for CFRP composites using new criteria. Compos Struct 201:1076-1087. https://doi.org/10.1016/j.compstruct.2018.06. 051

20. Aurich JC, Dornfeld D, Arrazola PJ et al (2009) Burrs-analysis, control and removal. CIRP Ann 58:519-542. https://doi.org/10. 1016/j.cirp.2009.09.004

21. Li M, Huang M, Jiang X et al (2018) Study on burr occurrence and surface integrity during slot milling of multidirectional and plain woven CFRPs. Int J Adv Manuf Technol 97:163-173. https://doi.org/10.1007/s00170-018-1937-6

22. Dong S, Liao W, Zheng K et al (2018) Investigation on exit burr in robotic rotary ultrasonic drilling of CFRP/aluminum stacks. Int J Mech Sci. https://doi.org/10.1016/j.ijmecsci.2018.12.039

23. Niknam SA, Songmene V (2014) Analytical modelling of slot milling exit burr size. Int J Adv Manuf Technol 73:421-432. https://doi.org/10.1007/s00170-014-5758-y

24. Póka G, Mátyási G, Németh I (2016) Burr minimisation in face milling with optimised tool path. Procedia CIRP 57:653-657. https://doi.org/10.1016/j.procir.2016.11.113

25. Park KM, Kurniawan R, Yu Z, Ko TJ (2018) Evaluation of a hybrid cryogenic deburring method to remove uncut fibers on carbon fiber-reinforced plastic composites. Int J Adv Manuf Technol. https://doi.org/10.1007/s00170-018-3045-Z

26. Davim JP, Rubio JC, Abrao AM (2007) A novel approach based on digital image analysis to evaluate the delamination factor after drilling composite laminates. Compos Sci Technol 67:1939_ 1945. https://doi.org/10.1016/j.compscitech.2006.10.009

27. Poór DI, Geier N, Pereszlai C, Xu J (2021) A critical review of the drilling of CFRP composites: Burr formation, characterisation and challenges. Compos Part B Eng 109155. https://doi. org/10.1016/j.compositesb.2021.109155

28. Hrechuk A, Bushlya V, Ståhl J-E (2018) Hole-quality evaluation in drilling fiber-reinforced composites. Compos Struct 204:378-387. https://doi.org/10.1016/j.compstruct.2018.07.105

29. Wang F, Yin J, Ma J et al (2017) Effects of cutting edge radius and fiber cutting angle on the cutting-induced surface damage in machining of unidirectional CFRP composite laminates. Int J Adv Manuf Technol 91:3107-3120. https://doi.org/10.1007/ s00170-017-0023-9

30. Ahmad JS, Shahid AH (2013) Effect of edge trimming on failure stress of carbon fibre polymer composites. Int J Mach Mach Mater 13:331. https://doi.org/10.1504/IJMMM.2013.053231

31. Gale WF, Totemeier TC (2004) 30 - metal cutting and forming. Smithells Metals Reference Book (Eighth Edition). ButterworthHeinemann, Oxford, pp 30-31

32. Geng D, Liu Y, Shao Z et al (2019) Delamination formation, evaluation and suppression during drilling of composite laminates: a review. Compos Struct 216:168-186. https://doi.org/10. 1016/j.compstruct.2019.02.099

33. Geier N, Pereszlai C (2020) Analysis of characteristics of surface roughness of machined CFRP composites. Period Polytech 64:67-80. https://doi.org/10.3311/PPme.14436

34. Xu J, Lin T, Davim JP et al (2021) Wear behavior of special tools in the drilling of CFRP composite laminates. Wear 203738. https://doi.org/10.1016/j.wear.2021.203738
35. Geier $N$ (2020) Influence of fibre orientation on cutting force in up and down milling of UD-CFRP composites. Int $\mathbf{J}$ Adv Manuf Technol 111:881-893. https://doi.org/10.1007/ s00170-020-06163-3

36. Gara S, Tsoumarev O (2016) Prediction of surface roughness in slotting of CFRP. Measurement 91:414-420. https://doi.org/ 10.1016/j.measurement.2016.05.016

37. Morkavuk S, Köklü U, Bağcı M, Gemi L (2018) Cryogenic machining of carbon fiber reinforced plastic (CFRP) composites and the effects of cryogenic treatment on tensile properties: a comparative study. Compos Part B Eng 147:1-11. https://doi. org/10.1016/j.compositesb.2018.04.024

38. Fu R, Jia Z, Wang F et al (2018) Drill-exit temperature characteristics in drilling of UD and MD CFRP composites based on infrared thermography. Int J Mach Tools Manuf 135:24-37. https://doi.org/10.1016/j.ijmachtools.2018.08.002

39. Pereszlai C, Geier N (2020) A comparative analysis of wobble milling, helical milling and conventional drilling of CFRP. Int J Adv Manuf Technol 106:3913-3930. https://doi.org/10.1007/ s00170-019-04842-4

40. Geier N, Póka G, Pereszlai C (2019) Monitoring of orbital drilling process in CFRP based on digital image processing of characteristics of uncut fibres. Procedia CIRP 85:16-170. https:// doi.org/10.1016/j.procir.2019.09.011

41. Pereszlai C, Geier N, Poór DI et al (2021) Drilling fibre reinforced polymer composites (CFRP and GFRP): An analysis of the cutting force of the tilted helical milling process. Compos Struct 262:113646. https://doi.org/10.1016/j.compstruct.2021. 113646

42. Franke V (2011) Drilling of long fiber reinforced thermoplastics-influence of the cutting edge on the machining results. CIRP Ann 60:65-68. https://doi.org/10.1016/j.cirp.2011.03.078

43. Balázs BZ, Takács M (2020) Experimental investigation of surface characteristics and dynamic effects at micro milling of hardened hot-work tool steel. Int J Mach Mach Mater 22:504. https://doi.org/10.1504/IJMMM.2020.111355

44. Wang C, Liu G, An Q, Chen M (2017) Occurrence and formation mechanism of surface cavity defects during orthogonal milling of CFRP laminates. Compos Part B Eng 109:10-22. https://doi.org/10.1016/j.compositesb.2016.10.015

45. Ashworth S, Fairclough JPA, Takikawa Y et al (2019) Effects of machine stiffness and cutting tool design on the surface quality and flexural strength of edge trimmed carbon fibre reinforced polymers. Compos Part Appl Sci Manuf 119:88-100. https:// doi.org/10.1016/j.compositesa.2019.01.019

46. Suresha B, Deepa Urs MV, Venkatesh HN et al (2021) Influence of fillers on mechanical behaviour of carbon fiber/vinyl ester hybrid composites. Mater Today Proc 43:1331-1336. https:// doi.org/10.1016/j.matpr.2020.09.165

47. Montarnal D, Capelot M, Tournilhac F, Leibler L (2011) Silicalike malleable materials from permanent organic networks. Science 334:965-968. https://doi.org/10.1126/science.1212648

Publisher's Note Springer Nature remains neutral with regard to jurisdictional claims in published maps and institutional affiliations. 